\title{
Erratum to: Current Trends in the Oncologic and Surgical Managements of Breast Cancer in Women with Implants: Incidence, Diagnosis, and Treatment
}

Paolo Veronesi ${ }^{1}$ - Francesca De Lorenzi ${ }^{2}$ - Pietro Loschi ${ }^{2}$ - Mario Rietjens ${ }^{2}$. Umberto Veronesi ${ }^{1}$

Published online: 7 July 2016

(c) Springer Science+Business Media New York and International Society of Aesthetic Plastic Surgery 2016

Erratum to: Aesth Plast Surg (2016) 40:256-265

DOI 10.1007/s00266-016-0612-2

The Given Names and Family Names were inadvertently inverted. The correct order is Paolo Veronesi, Francesca De Lorenzi, Pietro Loschi, Mario Rietjens and Umberto Veronesi.

The online version of the original article can be found under doi:10. 1007/s00266-016-0612-2.

Francesca De Lorenzi

francesca.delorenzi@ieo.it

1 Department of Surgery, European Institute of Oncology, Via Ripamonti 435, 20141 Milan, Italy

2 Department of Plastic and Reconstructive Surgery, European Institute of Oncology, Via Ripamonti 435, 20141 Milan, Italy 